\title{
Ability of $S$-Methyl-L-cysteine to Annul the Inhibition of Yeast Growth by L-Ethionine and by $S$-Ethyl-L-cysteine
}

\author{
By G. A. MAW \\ Arthur Guinness Son and Co. (Dublin) Ltd., Dublin, Eire
}

(Received 23 January 1961)

\begin{abstract}
SUMMARY
The inhibition of growth of a brewer's yeast and four other yeasts by L-ethionine, and the annulment of the inhibition by L-methionine were examined. $S$-MethylL-cysteine, DL-methionine sulphoxide and DL- $\alpha$-amino- $n$-butyric acid were also able to decrease the growth inhibition. At a fivefold molar concentration, $S$-methylcysteine annulled completely the effect of ethionine on the brewer's yeast. $S$-Ethyl$\mathrm{L}$-cysteine was ineffective and in certain conditions it acted as a growth inhibitor; this inhibition was annulled by methionine and by $S$-methylcysteine.
\end{abstract}

\section{INTRODUCTION}

The inhibitory effect of ethionine on microbial growth was first observed by Harris \& Kohn (1941) with Escherichia coli. These workers also recognized the ability of methionine to abolish the growth inhibition, thus supporting the original suggestion of Dyer (1938) that ethionine is a metabolic antagonist of methionine. Ethionine inhibition of growth in $E$. coli was also reported by Roblin et al. (1945) and a similar effect with baker's yeast was obtained by Loveless, Spoerl \& Weisman (1954). The antagonistic effect of ethionine on methionine utilization has also been shown with Lactobacillus arabinosus (Camien \& Dunn, 1950) and L. mesenteroides (Kihara \& Snell, 1955). It has been found that ethionine is not metabolically inert, but undergoes a number of reactions analogous to those characteristic of methionine. In Torula utilis and baker's yeast it is converted to 5 '-ethylthioadenosine (Schlenk \& Tillotson, 1954 $a$ ) and $S$-adenosylethionine (Parks, 1958), the latter compound being capable of undergoing transethylation in yeast. The intact molecule of ethionine has been shown to enter into the cell protein of Tetrahymena pyriformis (Gross \& Tarver, 1955) and into the $\alpha$-amylase of Bacillus subtilis (Yoshida, 1958; Yoshida \& Yamasaki, 1959). Ethionine may therefore inhibit growth through a number of mechanisms, for example, by competition with methionine, thereby blocking essential transmethylation systems, by undergoing transethylation reactions resulting in the formation and accumulation of ethyl analogues of important methylated metabolites, and by participating in protein synthesis with the formation of abnormal proteins containing ethionine in place of methionine. The present paper describes a further examination of the ethionine inhibition of yeast growth, in which a number of compounds related structurally to methionine have been tested for their ability to annul the inhibition. One compound which is effective in 
this respect is $S$-methyl-L-cysteine. It was also found that under certain conditions $S$-ethyl-L-cysteine exhibits growth-inhibitory properties which, like those of ethionine, are annulled by methionine and by $S$-methylcysteine.

\section{METHODS}

Yeasts. The brewer's yeast used was a Guinness strain of Saccharomyces cerevisiae as in previous studies (Maw, 1960, 1961). The other yeasts used were a baker's yeast, a strain of $S$. carlsbergensis (NCTC 7014), a strain of Torula utilis (NCTC 3576) and a strain of Candida lipolytica (Harrison) Diddens \& Lodder.

Compounds used. S-Methyl-L-cysteine was prepared by the reduction and subsequent methylation of L-cystine in anhydrous ammonia (du Vigneaud, Loring \& Craft, 1934). The other compounds used were commercial samples, obtained from British Drug Houses Ltd., the Nutritional Biochemicals Corporation, or the California Foundation for Biochemical Research. The following amino acids were obtained in the form of their L-isomers: methionine, ethionine, $S$-methylcysteine, $S$-ethylcysteine, cysteine, glutamic acid and aspartic acid. The remaining amino acids were available only in their DL-forms.

Media. The growth medium used for the brewer's yeast was similar to that described previously (Maw, 1960) but with the following additions (the amounts given are for 1 l. final medium): $\mathrm{CuCl}_{2} .2 \mathrm{H}_{2} \mathrm{O}, 180 \mu \mathrm{g}$.; $\mathrm{Na}_{2} \mathrm{MoO}_{4} \cdot 2 \mathrm{H}_{2} \mathrm{O}, 170 \mu \mathrm{g}$.; $\mathrm{H}_{3} \mathrm{BO}_{3}, 300 \mu \mathrm{g}$; $\left(\mathrm{CH}_{3} \cdot \mathrm{CO}_{2}\right)_{2} \mathrm{Zn} .2 \mathrm{H}_{2} \mathrm{O}, 3 \cdot 4 \mathrm{mg}$. Sulphate was added to a final concentration of $0.312 \mathrm{~mm}$ (10 mg. sulphate-S/1.). This medium is hereafter referred to as the sulphate medium. The yeast was also made sulphur-deficient by growing it in a sulphate-free medium. This corresponded in composition to the sulphate medium except that sodium sulphate was omitted. The other yeasts were grown on the sulphate medium further supplemented with $p$-aminobenzoic acid (100 $\mu \mathrm{g} . / 1$. and nicotinic acid (100 $\mu \mathrm{g}$./l.).

Growth experiments. Yeasts were grown for 2 days at $30^{\circ}$. The organisms were then centrifuged off, resuspended three times in sterile saline and recentrifuged, and then suspensions prepared in saline to contain about $0.3 \mathrm{mg}$. dry weight yeast $/ \mathrm{ml}$. Growth experiments were carried out in $25 \mathrm{ml}$. conical flasks containing $10 \mathrm{ml}$. medium and other reagents to which was added $0.5 \mathrm{ml}$. yeast suspension. Flasks were shaken at $30^{\circ}$ in a thermostat and the amount of growth determined turbidimetrically after $40 \mathrm{hr}$. (Maw, 1960).

\section{RESULTS}

\section{Experiments with L-ethionine}

Effect of L-ethionine on yeast growth. The effect of various concentrations of L-ethionine on the growth of the brewer's yeast in a medium containing $0.312 \mathrm{~mm}$ sulphate was examined. When the yeast had been grown previously on the sulphate medium, 0.312 mm-ethionine produced a growth inhibition of 90-100\%, whereas growth inhibition was small with concentrations below $10 \mu \mathrm{M}$ (see Fig. $1 a$ ).

The yeast was made sulphur deficient by growing it for several weeks in a sulphate-free medium. When it was then tested for growth in the sulphate medium in the presence of ethionine it was found to be markedly more sensitive to the inhibitor. Complete growth inhibition was obtained with ethionine at concentrations down to $3 \cdot 12 \mu \mathrm{M}$; at $0 \cdot 78 \mu \mathrm{M}$ a $69 \%$ inhibition was observed (see Fig. $1 b$ ). 
In the case of the four other yeasts studied, the growth of Candida lipolytica was partially suppressed (31 \%) by $31.2 \mu$ M ethionine, that of the baker's yeast, Saccharomyces carlsbergensis and Torula utilis being unaffected. At 0.312 mM ethionine produced complete growth inhibition of $C$. lipolytica, $S$. carlsbergensis and $T$. utilis, but only partial growth inhibition $(67 \%$ ) of baker's yeast. Increasing the ethionine to $1.56 \mathrm{~mm}$ only increased the growth inhibition of baker's yeast to $83 \%$.

Effect of L-methionine on the inhibition of growth caused by ethionine. Equimolar amounts of L-methionine completely annulled growth inhibition in the normal brewer's yeast at all concentrations of L-ethionine used (31.2 $\mu \mathrm{M}$ to $1.56 \mathrm{mM})$. Lower

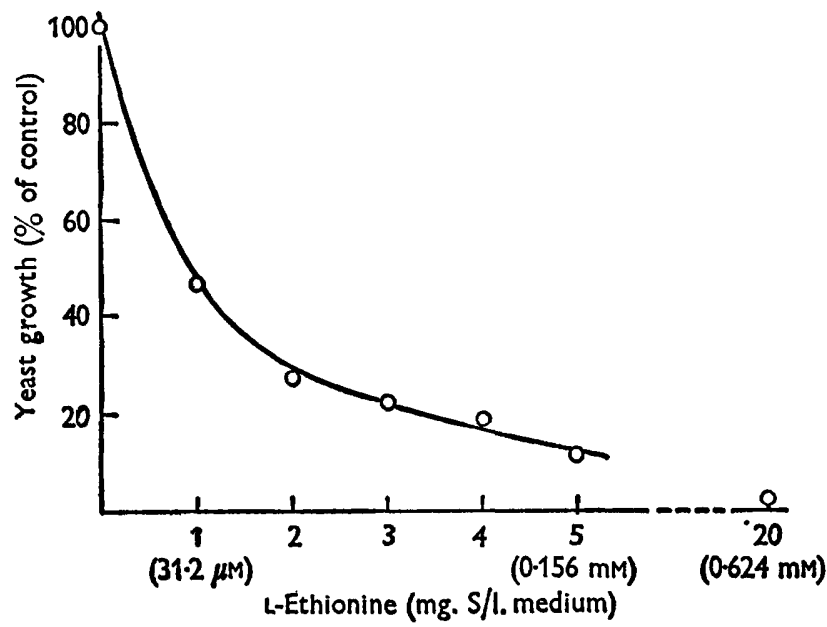

Fig. $1 a$

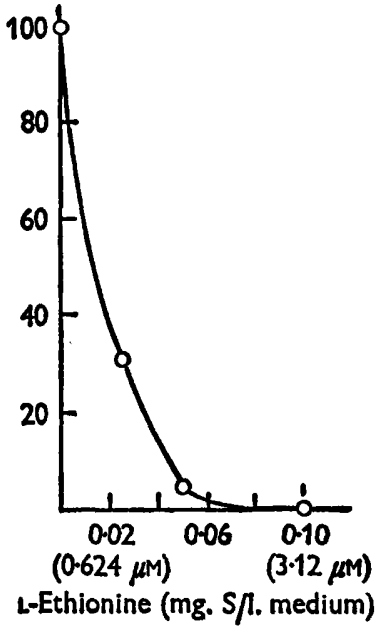

Fig. $1 b$

Fig. 1a. Effect of L-ethionine on the growth of normal brewer's yeast.

Fig. 1b. Effect of L-ethionine on the growth of sulphur-deficient brewer's yeast.

concentrations of methionine produced only partial decrease of the inhibition. This is illustrated in Fig. $2 a$ for ethionine at $0.312 \mathrm{~mm}$. Essentially similiar results were obtained when methionine was present in the medium as the sole source of sulphur for growth. Methionine was also equally effective in annulling the inhibition in the sulphur-deficient brewer's yeast grown on the sulphate medium. Methionine $31 \cdot 2 \mu \mathrm{M}$ promoted full growth in the presence of the same concentration of ethionine, which alone produced complete growth inhibition. Growth inhibition by ethionine of the four other yeasts under study was also completely abolished by equimolar amounts of methionine.

Effect on ethionine inhibition of compounds related to methionine. The specificity of methionine in annulling ethionine inhibition of growth was studied with the brewer's yeast. The compounds examined included a number with close structural relationships to methionine and others which are known to be related metabolically to this amino acid. L-Ethionine was used at $0.312 \mathrm{~mm}$ and $1.56 \mathrm{~mm}$, and the various compounds under test were added at these concentrations and at five times these values. The findings obtained with the two ethionine concentrations were closely similar. Table 1 gives the summarized data obtained with $0.312 \mathrm{~mm}$ ethionine. It will be seen that in addition to methionine itself, only three compounds, namely 
DL-methionine sulphoxide, DL- $\alpha$-aminobutyric acid and $S$-methyl-L-cysteine possessed any marked ability to annul the inhibition. All three exerted an effect at five times the ethionine concentration, but at equimolar concentrations methionine sulphoxide was ineffective while the other two compounds were only slightly

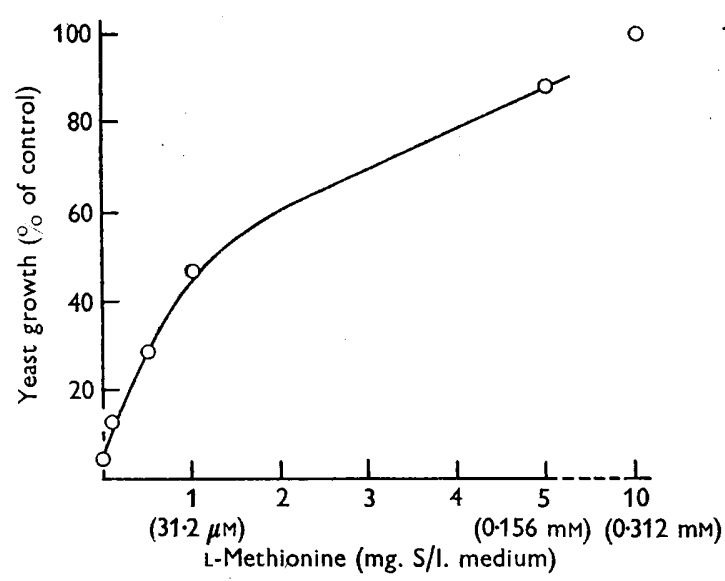

Fig. $2 a$

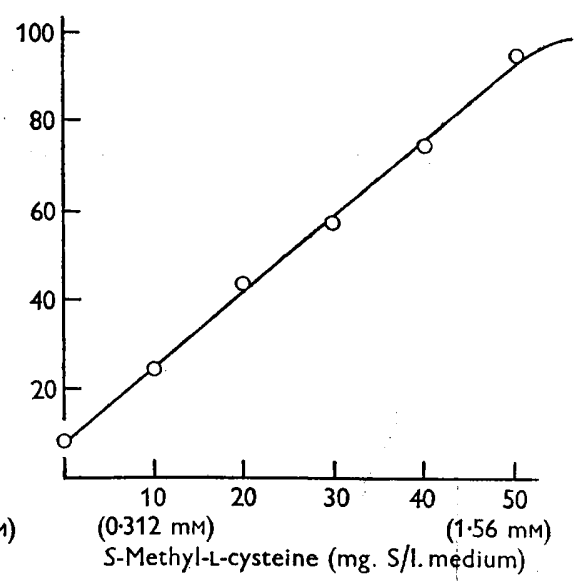

Fig. $2 b$

Fig. 2a. Annulment by L-methionine of the growth-inhibitory effect of L-ethionine $(0 \cdot 312 \mathrm{~mm})$ on brewer's yeast.

Fig. $2 b$. Annulment by $S$-methyl-L-cysteine of the growth-inhibitory effect of L-ethionine $(0 \cdot 312 \mathrm{~mm})$ on brewer's yeast.

Table 1. Effect of various compounds related to methionine on the inhibition of growth of brewer's yeast by L-ethionine

L-Ethionine in medium at $0.312 \mathrm{~mm}(10 \mathrm{mg}$. ethionine-S/1.). Added compounds at $0.312 \mathrm{~mm}$ and $1.56 \mathrm{~mm}$. Growth of yeast determined in flasks shaken for $40 \mathrm{hr}$. at $30^{\circ}$ and expressed as \% of the growth obtained in the sulphate medium in the absence of ethionine. Growth in the presence of L-ethionine (0.312 mu) alone $5.4 \%$.

Growth of yeast when added compound was

Added compound

$S$-Methyl-DL-methionine chloride DL-Methionine sulphoxide

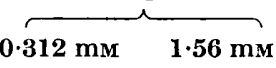

DL-Methionine sulphone

$\alpha$-Ketomethionine

Relative growth (\%)

DL-Homocysteine

$\begin{array}{rr}11 \cdot 8 & 12 \cdot 1 \\ 4 \cdot 0 & 99 \cdot 1 \\ 1.0 & 16 \cdot 5 \\ 4 \cdot 6 & 24 \cdot 1 \\ 6 \cdot 0 & 13 \cdot 1 \\ 18 \cdot 3 & 51 \cdot 5 \\ 8 \cdot 0 & 16 \cdot 4 \\ 11 \cdot 0 & 17 \cdot 7 \\ 9 \cdot 9 & 15 \cdot 0 \\ 7 \cdot 3 & 5 \cdot 1 \\ 2 \cdot 5 & 14 \cdot 4 \\ 21 \cdot 5 & 94 \cdot 0 \\ 5.9 & 10 \cdot 0 \\ 5 \cdot 9 & 5.9 \\ 31 \cdot 4 & -\end{array}$

DL-Homoserine

L-Glutamic acid

L-Aspartic acid

L-Cysteine

Glutathionine (reduced)

$S$-Methyl-L-cysteine

$S$-Ethyl-L-cysteine

Sodium methylthioacetate

$S$-Methyl-L-cysteine $(0 \cdot 312 \mathrm{~mm})+$ DL- $\alpha$-amino- $n$-butyric acid (0.312 mM)

16.5

24.1

$16 \cdot 4$

$7 \cdot 7$

$94 \cdot 0$

$0 \cdot 0$

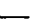


effective. Other compounds tested included adenine, adenosine and $p$-aminobenzoic acid. None of these had any effect on the inhibition.

Effect of S-methyl-L-cysteine on the growth inhibition by ethionine. The ability of $S$-methyl-L-cysteine to antagonize the growth inhibition due to L-ethionine is further illustrated in Fig. 2b. (The medium contained sulphate as the sulphur source together with $0.312 \mathrm{~mm}$-ethionine). For ethionine concentrations within the range $31 \cdot 2 \mu \mathrm{M}$ to $1.56 \mathrm{~mm}$ equimolar amounts of $S$-methylcysteine generally decreased the growth inhibition by 20-30\%, but a fivefold concentration restored growth completely or almost so.

$S$-Methylcysteine also decreased the growth inhibition of other yeasts, although its effect was somewhat less marked than with the brewer's yeast (see Table 2).

Table 2. Effect of L-methionine and of S-methyl-L-cysteine in annulling the growth inhibition due to L-ethionine in various yeasts

L-Ethionine in medium $\mathbf{0 . 3 1 2} \mathrm{mm}$. Growth of yeasts determined in flasks shaken for $40 \mathrm{hr}$. at $30^{\circ}$ and expressed as $\%$ of the growth obtained in the sulphate medium in the absence of ethionine.

\begin{tabular}{|c|c|c|c|c|}
\hline \multirow[b]{3}{*}{ Yeast } & \multicolumn{4}{|c|}{$\%$ Inhibition of growth in the presence of } \\
\hline & \multirow{2}{*}{$\begin{array}{c}\text { Ethionine } \\
\text { alone } \\
\text { (0.312 mM) }\end{array}$} & \multirow{2}{*}{$\begin{array}{l}\text { Ethionine } \\
(0.312 \mathrm{~mm})+ \\
\text { methionine } \\
(0.312 \mathrm{~mm})\end{array}$} & \multicolumn{2}{|c|}{$\begin{array}{c}\text { Ethionine } \\
(0 \cdot 312 \mathrm{~mm})+ \\
S \text {-methylcysteine }\end{array}$} \\
\hline & & & $(0.312 \mathrm{mM})$ & (1.56 mM) \\
\hline Baker's yeast & $67 \cdot 3$ & $\mathbf{0}$ & $46 \cdot 8$ & $\mathbf{0}$ \\
\hline S. carlsbergensis & 100 & $12 \cdot 5$ & 100 & $52 \cdot 9$ \\
\hline C. lipolytica & $97 \cdot 7$ & $\mathbf{3 \cdot 5}$ & 70.5 & $36 \cdot 2$ \\
\hline T. utilis & $96 \cdot 5$ & $3 \cdot 5$ & 100 & $50 \cdot 8$ \\
\hline
\end{tabular}

\section{Experiments with S-ethyl-L-cysteine}

S-Ethyl-L-cysteine and yeast growth. In view of the relationships between ethionine, methionine and $S$-methylcysteine in connexion with yeast growth, it seemed of interest to examine the related compound $S$-ethyl-L-cysteine to determine whether it paralleled $S$-methylcysteine in protecting against ethionine inhibition or whether it resembled ethionine in being itself growth inhibitory. At concentrations up to $3 \cdot 12 \mathrm{~mm}$ in an otherwise sulphur-deficient medium $S$-ethylcysteine was completely unable to act as a sulphur source, in contrast to $S$-methylcysteine (Maw, 1960, 1961). Furthermore, unlike $S$-methylcysteine, the ethyl compound showed no detectable ability to annul growth inhibition by $0 \cdot 312 \mathrm{~mm}$-ethionine, even when present at ten times this concentration (see also Table 1).

Growth of the brewer's yeast and the four other yeasts studied in the sulphate medium was also not suppressed by $S$-ethylcysteine itself at concentrations up to 3.12 mM. However, the compound showed distinct growth-inhibitory properties towards the brewer's yeast $(a)$ when the yeast was first made sulphur-deficient before being tested for growth in the sulphate medium, or $(b)$ when it was grown in a medium containing $S$-methylcysteine as the sole sulphur source.

Effect of S-ethyl-L-cysteine on the growth of sulphur-deficient brewer's yeast. When made sulphur deficient the brewer's yeast proved to be particularly sensitive to the presence of $S$-ethyl-L-cysteine (see Fig. 3). $S$-Ethylcysteine was completely growth 


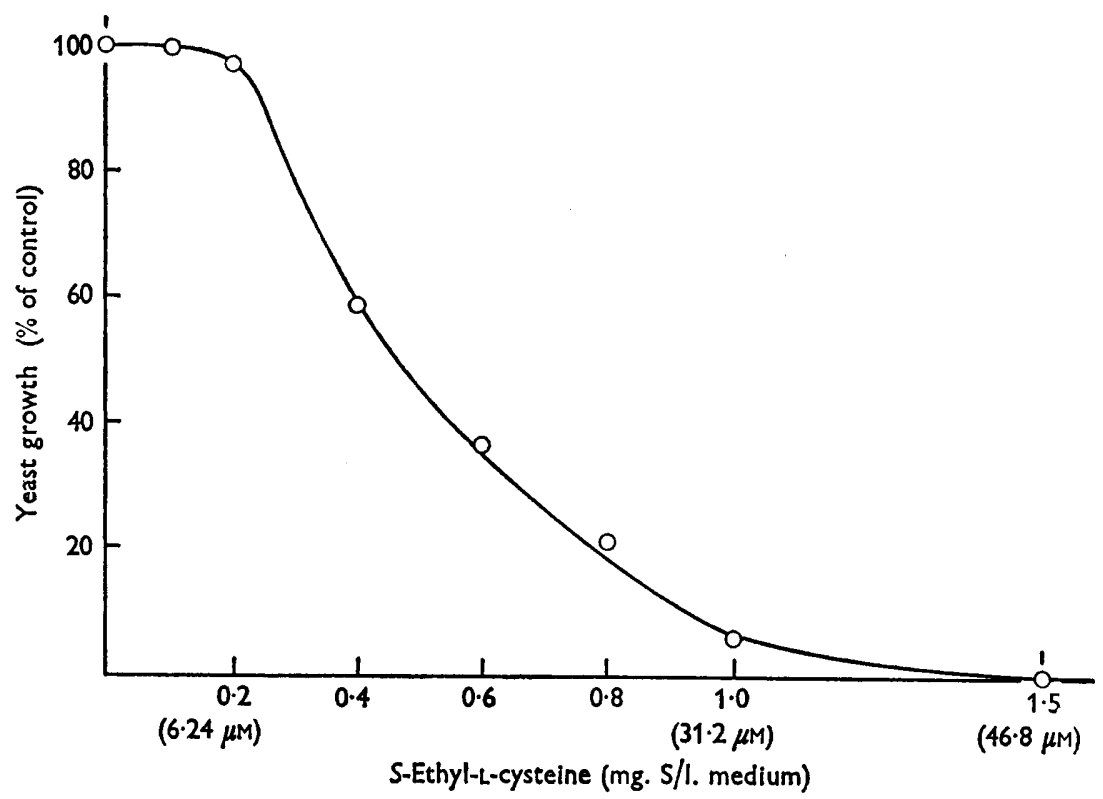

Fig. 3. Effect of $S$-ethyl-L-cysteine on the growth of sulphur-deficient brewer's yeast.

inhibitory at concentrations down to $31 \cdot 2 \mu \mathrm{M}$. This growth inhibition, like that produced by ethionine, was annulled by both L-methionine and $S$-methyl-L-cysteine (see Fig. $4 a$ and $4 b$; the $S$-ethylcysteine concentration in these experiments was 0.312 $\mathrm{mm}$ ). Methionine was the more active compound in annulling the inhibition. For concentrations of $S$-ethylcysteine in the medium within the range $0.312 \mathrm{~mm}$ to 3.12 mM, methionine at one-fourhundredth of the concentration produced complete

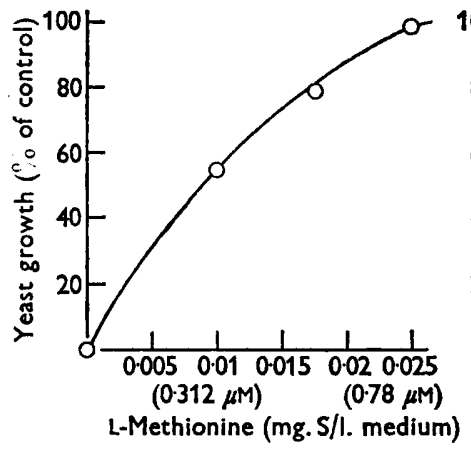

Fig. $4 a$

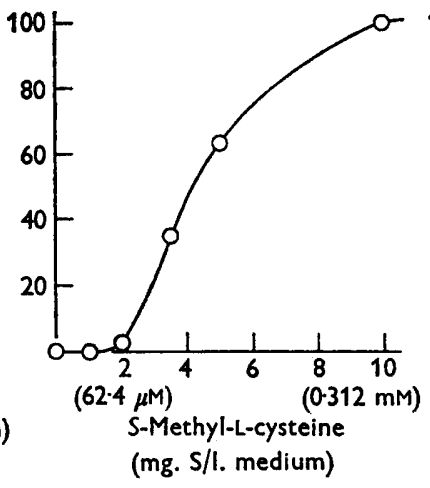

Fig. $4 \boldsymbol{b}$

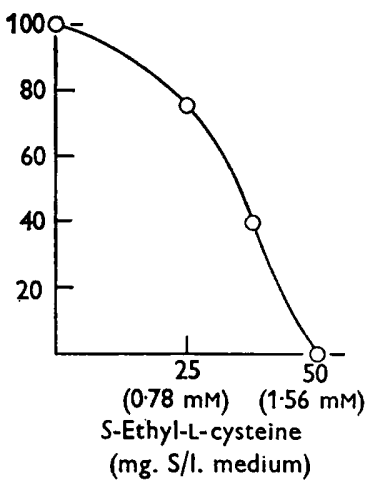

Fig. 5

Fig. 4a. Annulment by L-methionine of the growth-inhibitory effect of $S$-ethyl-Lcysteine $(0 \cdot 312 \mathrm{~mm})$ on sulphur-deficient brewer's yeast.

Fig. $4 b$. Annulment by $S$-methyl-L-cysteine of the growth-inhibitory effect of $S$-ethyl-Lcysteine (0.312 mM) on sulphur-deficient brewer's yeast.

Fig. 5. Effect of $S$-ethyl-L-cysteine on the growth of brewer's yeast in the presence of $S$-methyl-L-cysteine (0.312 mM) as sulphur source. 
restoration of growth, and even at one-thousandth of the concentration restored $\mathbf{5 0} \%$ growth. $S$-Methylcysteine gave complete restoration of growth when present in equimolar concentrations, but at lower concentrations it caused only partial annulment of the inhibition.

Growth inhibition of brewer's yeast with S-methyl-L-cysteine as sulphur source. Although the brewer's yeast grown in the presence of sulphate was unaffected by $S$-ethyl-L-cysteine even in relatively high concentrations, growth inhibition was observed when $S$-methyl-L-cysteine was made the sole sulphur source. Figure 5 shows the inhibitory effect of the ethyl compound in the presence of $0.312 \mathrm{~mm}-S$ methylcysteine. In contrast, when L-methionine (0.312 mu-1.56 mu) was used as the sulphur source, $S$-ethylcysteine showed no growth-inhibitory properties.

\section{DISCUSSION}

The evidence so far available points to the biological role of ethionine as a competitive antagonist of methionine in reactions subsequent to the synthesis of the latter, e.g. conversion to $S$-adenosylmethionine (Parks, 1958) and incorporation into protein (Gross \& Tarver, 1955). The present work indicates that only a very limited number of compounds acted like methionine in annulling growth inhibition by ethionine. The effectiveness of methionine sulphoxide in this respect seems most probably to be accounted for by the recent demonstration by Black et al. (1960) of an enzyme system in yeast which catalyses the reduction of the sulphoxide to methionine. A somewhat unexpected finding was the inability of $S$-methylmethionine to annul ethionine inhibition, in view of the existence in yeast of a transmethylase capable of demethylating $S$-methylmethionine to methionine (Shapiro, 1958). Any explanation of this, however, would need to take into account the extent to which $S$-methylmethionine can penetrate the intact yeast cell, about which little is known.

The ability of $S$-methylcysteine to annul the growth inhibition points to a close metabolic link between this amino acid and methionine. $S$-Methylcysteine and its sulphoxide occur in the non-protein nitrogen fraction of various plants (Morris \& Thompson, 1955; Synge \& Wood, 1956; Thompson, Morris \& Zacharius, 1956), and there is evidence for its presence in the mycelium of Neurospora crassa (Ragland \& Liverman, 1956). Furthermore, Wolff, Black \& Downey (1956) demonstrated its enzymic synthesis in baker's yeast from methanethiol and serine. $S$-methylcysteine is able to act as a source of sulphur for the growth of certain yeasts (Margolis \& Block, 1958; Maw, 1960, 1961), Escherichia coli (Roberts et al. 1955) and certain strains of $N$. crassa (Ragland \& Liverman, 1956). In brewer's yeast, when present in sufficient amounts, it can promote optimum growth. The sulphur of $S$-methylcysteine is therefore available for the synthesis of methionine and other sulphur amino acids. However, $S$-methylcysteine may be distinguished from other compounds capable of acting as sulphur sources, e.g. cysteine and glutathione, in that such compounds are ineffective in annulling the ethionine inhibition.

Three possible explanations to account for the antagonism between $S$-methylcysteine and ethionine have been considered: (i) $S$-methylcysteine may substitute for methionine in one or more reactions essential for growth which have been blocked by ethionine; (ii) $S$-methylcysteine may be a normal intermediate in certain 
reactions of methionine; (iii) in addition to blocking the further metabolism of methionine, ethionine may act as an inhibitor at some stage in methionine synthesis from sulphate and cysteine, and $S$-methylcysteine may abolish the ethionine effect either $(a)$ by entering the pathway of methionine synthesis above this step, or $(b)$ by giving rise to methionine by a separate pathway unaffected by ethionine.

There is no clear-cut evidence to support (i) or (ii). The apparent absence of $S$-methylcysteine from proteins argues against (i). Furthermore, if (ii) were correct, $S$-methylcysteine would need to be an intermediate in the major metabolic reactions of methionine, such as protein synthesis and $S$-adenosylmethionine formation, for the compound to be able to bypass completely the growth-inhibitory effects of ethionine.

The most tenable explanation seems to be (iii). Since cysteine is unable to annul ethionine inhibition, it is unlikely that $S$-methylcysteine gives rise to methionine through the intermediate formation of cysteine, and this would at the same time imply that ethionine inhibits at a stage in the synthesis after cysteine. Conversion of $S$-methylcysteine to cysteine also seems unlikely from the observation of Ragland \& Liverman (1956) that the methyl compound acts as a sulphur source for strains of Neurospora crassa able to grow on methionine but unable to utilize cysteine. The idea of a separate pathway from $S$-methylcysteine to methionine, not involving cysteine, is suggested by the work of Wolff et al. (1956) and Schlenk \& Tillotson $(\mathbf{1 9 5 4} b)$ on the conversion in yeast of methanethiol to $S$-methylcysteine and $5^{\prime}$-methylthioadenosine. This is believed to proceed by the following scheme:

$$
\begin{aligned}
\text { methanethiol } \stackrel{\text { serine }}{\longrightarrow} S \text {-methylcysteine } \stackrel{\mathrm{C}_{4} \text {-compound }}{\longrightarrow} \text { methionine } \\
\downarrow \text { ATP } \\
5^{\prime} \text {-methylthioadenosine } \leftarrow S \text {-adenosylmethionine }
\end{aligned}
$$

The identity of the intermediates between $S$-methylcysteine and methionine is not known, but the step is thought to be a transthiomethylation to a $\mathrm{C}_{4}$-compound. In this connexion, it was found in the present work that an equimolar mixture of $S$-methylcysteine and $\alpha$-aminobutyric acid was unable to act in place of an equivalent amount of methionine in annulling ethionine inhibition (see Table 1 ).

The annulment of the growth-inhibitory effect of $S$-ethylcysteine by methionine and by $S$-methylcysteine further illustrates the metabolic link between these last two compounds. $S$-Ethylcysteine was shown to be a tuberculostatic agent by Brown et al. (1954) and to inhibit penicillin synthesis in Penicillium chrysogenum by Demain (1956). This compound would be expected to block the incorporation and/or metabolism of $S$-methylcysteine. The annulment by extremely low concentrations of methionine of the growth inhibition due to $S$-ethylcysteine suggests a further site of action for the compound, possibly through the formation of ethionine or a related compound.

Thanks are expressed to Mr C. Coyne for skilled technical assistance, to $\mathrm{Dr} \mathbf{A}$. K. Mills for his interest, and to the Directors of Arthur Guinness Son and Co. (Dublin) Ltd., for permission to publish this work. 


\section{REFERENCES}

Black, S., Harte, E. M., Hudson, B. \& Wartofsky, L. (1960). A specific enzymatic reduction of $\mathrm{L}(-)$ methionine sulphoxide and a related nonspecific reduction of disulphides. J. biol. Chem. 235, 2910.

Brown, H. D., Matzuk, A. R., Becker, H. J., Conbere, J. P., Constantin, J. M., Solotorovsky, M., Winsten, S., Ironson, E. \& Quastel, J. H. (1954). The antituberculosis activity of some ethylmercapto compounds. J. Amer. chem. Soc. 76, 3860.

Camien, M. N. \& DunN, M. S. (1950). Antagonisms in the utilization of $\mathrm{D}$-amino acids by lactic acid bacteria. J. biol. Chem. 184, 283.

Demain, A. L. (1956). Inhibition of penicillin formation by amino acid analogs. Arch. Biochem. Biophys. 64, 74.

Du Vigneaud, V., Loring, H. S. \& Craft, H. A. (1934). J. biol. Chem. 105, 481.

Dyer, H. M. (1938). The synthesis of $S$-ethylhomocysteine (ethionine) and a study of its availability for growth. J. biol. Chem. 124, 519.

Gross, D. \& Tarver, H. (1955). The incorporation of ethionine into the proteins of Tetrahymena. J. biol. Chem. 217, 169.

Harris, J. S. \& KoHN, H. I. (1941). The specific antagonism between methionine and the sulphonamides in Escherichia coli. J. Pharmacol. 73, 383.

Kinara, H. \& Snell, E. E. (1955). Peptides and bacterial growth. J. biol. Chem. 212, 83.

Loveless, L. E., Spoerl, E. \& Weisman, T. H. (1954). A survey of effects of chemicals on division and growth of yeast and Escherichia coli. J. Bact. 68, 637 .

Margolis, D. \& Block, R. J. (1958). The sulphur metabolism of yeast. Contr. Boyce Thompson Inst. 19, 437.

Maw, G. A. (1960). Utilization of sulphur compounds by a brewer's yeast. J. Inst. Brew. 66, 162.

MAw, G. A. (1961). Effects of cysteine and other thiols on the growth of a brewer's yeast. J. Inst. Brew. 67, 57.

Morris, C. J. \& Thompson, J. F. (1955). Isolation of $L(+)-S$-methylcysteine sulphoxide from turnip roots. Chem. \& Ind. p. 951.

PARKs, L. W. (1958). S-Adenosylethionine and ethionine inhibition. J. biol. Chem. 232, 169.

Ragland, J. B. \& Liverman, J. L. (1956). S-Methyl-L-cysteine as a naturally-occurring metabolite in Neurospora crassa. Arch. Biochem. Biophys. 65, 574.

Roberts, R. B., Abelson, P. H., Cowie, D. B., Bolton, E. T. \& Britten, R. J. (1955). Studies of biosynthesis in Escherichia coli. Washington: Carnegie Institute of Washington. Publication no. 607, p. 332.

Roblin, R. O., Lampen, J. O., English, J. P., Cole, Q. P. \& Vaughan, J. R. (1945). Methionine and purine antagonists and their relation to the sulphonamides. J.Amer. chem. Soc. 67, 290.

Schlenk, F. \& Tillotson, J. A. (1954a). Formation of 5'-ethylthioadenosine from DL-ethionine in yeast. J. biol. Chem. 206, 687 .

Schlenk, F. \& Tillotson, J. A. (1954b). Formation of 5 '-methylthioadenosine from methyl mercaptan in yeast. Fed. Proc. 13, 290.

ShapIro, S. K. (1958). Adenosylmethionine-homocysteine transmethylase. Biochim. biophys. Acta, 29, 405.

Synge, R. L. M. \& Wood, J. C. (1956). (+)-(S-Methyl-L-cysteine $S$-oxide) in cabbage. Biochem. J. 64, 252.

Thompson, J. F., Morris, C. J. \& Zacharius, R. M. (1956). Isolation of (-)-S-methyl-Lcysteine from beans (Phaseolus vulgaris). Nature, Lond. 178, 593.

WolfF, E. C., Black, S. \& Downey, P. F. (1956). Enzymatic synthesis of $S$-methylcysteine. J. Amer. chem. Soc. 78, 5958.

Yoshida, A. (1958). Studies on the mechanism of protein synthesis: bacterial $\alpha$-amylase containing ethionine. Biochim. biophys. Acta, 29, 213.

Yoshida, A. \& YAMASAKI, M. (1959). Studies on the mechanism of protein synthesis: incorporation of ethionine into $\alpha$-amylase of Bacillus subtilis. Biochim. biophys. Acta, 34, 158. 